\title{
Peptide Mass Fingerprinting and N-Terminal Amino Acid Sequencing of Glycosylated Cysteine Protease of Euphorbia nivulia Buch.-Ham.
}

\author{
Shamkant B. Badgujar ${ }^{1,2}$ and Raghunath T. Mahajan ${ }^{2}$ \\ ${ }^{1}$ Department of Biotechnology, Faculty of Science, Post Graduate College of Science, Technology and Research, \\ North Maharashtra University, Jalgaon, Maharashtra 425002, India \\ ${ }^{2}$ Department of Biotechnology, Faculty of Science, Moolji Jaitha College, Jalgaon, Maharashtra 425002, India
}

Correspondence should be addressed to Shamkant B. Badgujar; sham83badgujar@gmail.com

Received 24 October 2012; Revised 30 December 2012; Accepted 30 December 2012

Academic Editor: Hieronim Jakubowski

Copyright (C) 2013 S. B. Badgujar and R. T. Mahajan. This is an open access article distributed under the Creative Commons Attribution License, which permits unrestricted use, distribution, and reproduction in any medium, provided the original work is properly cited.

\begin{abstract}
A new cysteine protease named Nivulian-II has been purified from the latex of Euphorbia nivulia Buch.-Ham. The apparent molecular mass of Nivulian-II is 43670.846 Da (MALDI TOF/MS). Peptide mass fingerprint analysis revealed peptide matches to Maturase K (Q52ZV1_9MAGN) of Banksia quercifolia. The N-terminal sequence (DFPPNTCCCICC) showed partial homology with those of other cysteine proteinases of biological origin. This is the first paper to characterize a Nivulian-II of E. nivulia latex with respect to amino acid sequencing.
\end{abstract}

\section{Introduction}

Proteases are enzymes which potentially hydrolyze anything that contains peptide bond, from a dipeptide up to a large protein, containing thousands of amino acids and, thus, it comprises a group of hydrolases that are the most relevant in technological terms. Proteolytic enzymes have been the subject of intensive studies for a number of years because proteases have great therapeutic and industrial applications as well [1]. Peptidases in which the nucleophile that attacks the scissile peptide bond is the sulfhydryl group of a cysteine residue are known as cysteine-type peptidase. Many plant proteases have been isolated from the lattices and most of them belong to this catalytic type. Plant cysteine proteases belong to a class which has been widely studied over the years. These enzymes are also used in industries owing to their high stability [2]. Plant cysteine proteases play a major role in the intracellular and extracellular process such as development and ripening of fruits, degradation of storage proteins in germinating seeds, activation of proteins, and degradation of defective proteins [3]. Besides, latex proteases are also involved in the protection of the plants against predator attack [4]. Many researchers have isolated and characterized the plant origin proteases of diverse group.

Euphorbia nivulia Buch.-Ham. is a wild, thorny, xerophytic, succulent plant, found in boundaries of the agricultural field and also in dry barren areas. The secretion of milky juice is a characteristic property of this plant. Phytochemical studies have led to the isolation of ingol diterpenes (3-acetyl8-methoxyl-7-angolyl-12-hydroxylingol; 3,12-diacetyl-7-hydroxy-8-methoxylingol; 3,12-diacetyl-7-angolyl-8-hydroxylingol; 3,12-diacetyl-8-benzoylingol; and 3,12-diacetyl-7benzoyl-8-nicotinylingol) along with three macrocyclic ingol diterpenes derivatives (3,7,12-triacetyl-8-benzoylingol; 3,12diacetyl-7-angeloyl-8-methoxyingol; and 7-angeloyl-12-acetyl-8-methoxyingol) [5]. The latex of E. nivulia has been cited for its antioxidant, immunomodulator, cytotoxic, anti-inflammatory, wound healing, haemostatic, and antiproliferative activity [6]. During the course of screening for biochemical constituents, a substantial amount of proteolytic and milk clotting activity was found in the latex of this plant [7]. Recently, an attempt has been made on peptide 
TABLE 1: Calculated and observed ions of trypsin digests of Nivulian-II.

\begin{tabular}{|c|c|c|c|c|c|c|}
\hline \multirow{3}{*}{ Peak number } & \multirow{3}{*}{ Intensity } & \multicolumn{2}{|c|}{ Amino acid sequence } & \multirow{3}{*}{ Sequence } & \multicolumn{2}{|c|}{$[\mathrm{M}+\mathrm{H}]^{+}$} \\
\hline & & From & To & & Calculated & Observed \\
\hline & & & & & \multicolumn{2}{|c|}{$m / z$} \\
\hline 02 & 13226.59 & 115 & 122 & LVSSLEGK & 832.477 & 832.490 \\
\hline 18 & 3770.272 & 183 & 189 & FFLYEYR & 1037.509 & 1037.590 \\
\hline 19 & 3540.355 & 275 & 282 & DPFIHYVR & 1046.542 & 1046.635 \\
\hline 27 & 5762.630 & 283 & 292 & YQAKSFLAAR & 1154.632 & 1154.597 \\
\hline 30 & 2878.922 & 223 & 231 & CESMFVFLR & 1188.554 & 1188.631 \\
\hline 31 & 3792.376 & 190 & 199 & NWNSFITPKK & 1234.658 & 1234.750 \\
\hline 52 & 5565.563 & 287 & 300 & SFLAARGTPLMMNK & 1552.797 & 1552.775 \\
\hline 54 & 71959.36 & 170 & 182 & VWVQDVPSLHLLR & 1561.885 & 1561.831 \\
\hline 67 & 3587.283 & 382 & 397 & AKFCNALGHPISKPVR & 1794.980 & 1794.938 \\
\hline 70 & 3325.145 & 350 & 365 & SQMLENSFLIDIAINK & 1851.952 & 1852.035 \\
\hline 73 & 5424.503 & 494 & 509 & VWYLDIIRINDLVNHD & 1998.044 & 1997.970 \\
\hline 90 & 1525.765 & 67 & 86 & MYQQNHFIISSNSNSSNQNK & 2357.057 & 2357.131 \\
\hline 98 & 1297.007 & 63 & 86 & FIDRMYQQNHFIISSNSNSSNQNK & 2872.343 & 2872.537 \\
\hline
\end{tabular}

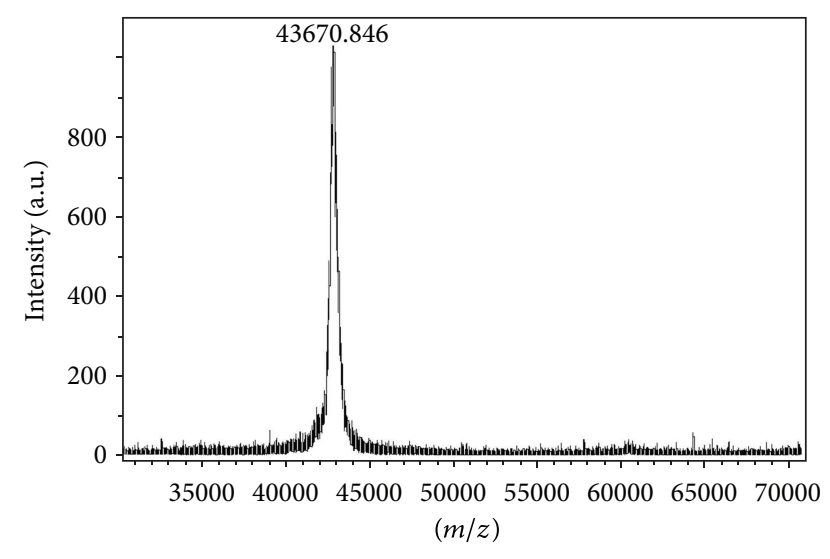

Figure 1: Mass spectroscopy of Nivulian-II of Euphorbia nivulia latex.

sequencing of 31-kDa, Tubulin alpha-1 chain-like protein called nivulian-I, present in the latex of E. nivulia [8]. Very recently, a comparative account on proteolytic activity of E. nivulia and other three plants, namely, Calotropis procera, Carica papaya, and Ficus carica, was reported by us. Additionally, we characterized the glycosylated cysteine protease called Nivulian-II of the latex of E. nivulia [5]. This paper describes the biochemical characterization, of this cysteine like protease with respect to peptide fingerprinting and N-terminal amino acid sequencing.

\section{Materials and Methods}

2.1. Chemicals. Sigma Chemicals: phenyl isothiocyanate (PITC), N-methylpiperidine, Methanol, Trifluoroacetic acid, Dithiothreitol, Acetonitrile, 20 Amino acid PTH standards, etc. were thankfully gifted by theDepartment of Biochem- istry, Indian Institute of Science, Bangalore (Karnataka), India. Sequencing grade Hybond-PVDF membrane (Amershyam) was gifted by the Department of Biochemistry, TMC, Advanced centre for Treatment, Research and Education in Cancer (ACTREC), Navi Mumbai, India. All other chemicals were of the highest purity, analytical HPLC grade purchased from Himedia Laboratories, Mumbai; SRL Chemicals, Bangalore; Qualigen Fine Chemicals, Mumbai; Merck Chemicals, India; and Bangalore Genie, India.

2.2. Plant Material, Collection of Latex, Crude Enzyme Preparation, and Purification of Cysteine Protease. The detail information about identification, collection, preservation, preparation of crude enzyme and its proteolytic activity of Euphorbia nivulia latex is described in our previous communication [7]. Method of purification of protease was done using acetone precipitation, DEAE cellulose chromatography, dialysis and followed by rechromatography on DEAE cellulose column as described in our earlier communication [5].

2.3. Mass Spectroscopy. Matrix-assisted laser desorption ionization/time of flight mass spectroscopy (MALDI/TOF MS) was used for the determination of the molecular mass, as well as the degree of purity of active enzyme. MALDI/TOF mass spectra were acquired on a Bruker Daltoncs model Ultraflex II Spectrometer, Germany, equipped with a pulsed Neodymium yttrium-aluminium garnet (Nd-YAG) smart beam solid state laser $(337 \mathrm{~nm})$, in reflectron positive-ion mode, using a 19-kV acceleration voltage. Enzyme samples were prepared by mixing equal volumes of a saturated solution of the matrix that is, sinapinic acid (prepared in $0.1 \%$ TFA (aq.) and 50\% acetonitrile (2:1)). $2 \mu \mathrm{L}$ matrix solution and $2 \mu \mathrm{L}$ protein (enzyme) fraction were spotted on the sample plate, mixed them, and allowed to evaporate to dryness. Proteins of known molecular mass (insulin, 
TABLE 2: Amino acid composition of peptides obtained from Nivulian-II by trypsin digestion.

\begin{tabular}{|c|c|c|c|c|c|c|c|c|c|c|c|c|c|c|}
\hline \multirow{2}{*}{ Amino acid } & \multicolumn{13}{|c|}{ Number of amino acids per peptide } & \multirow{2}{*}{ Tota } \\
\hline & $\mathrm{A}$ & $\mathrm{B}$ & $\mathrm{C}$ & $\mathrm{D}$ & $\mathrm{E}$ & $\mathrm{F}$ & G & $\mathrm{H}$ & $\mathrm{I}$ & $\mathrm{J}$ & $\mathrm{K}$ & $\mathrm{L}$ & $\mathrm{M}$ & \\
\hline Gly (G) & 1 & - & - & - & - & - & 1 & - & 1 & - & - & - & - & 03 \\
\hline Ala (A) & - & - & - & 3 & - & - & 2 & - & 2 & 1 & - & - & - & 08 \\
\hline $\operatorname{Val}(\mathrm{V})$ & 1 & - & 1 & - & 1 & - & - & 3 & 1 & - & 2 & - & - & 09 \\
\hline Leu (L) & 2 & 1 & - & 1 & 1 & - & 2 & 3 & 1 & 2 & 2 & - & - & 15 \\
\hline Ile (I) & - & - & 1 & - & - & 1 & - & - & 1 & 3 & 3 & 2 & 3 & 14 \\
\hline $\operatorname{Ser}(S)$ & 2 & - & - & 1 & 1 & 1 & 1 & 1 & 1 & 2 & - & 5 & 5 & 20 \\
\hline $\operatorname{Thr}(\mathrm{T})$ & - & - & - & - & - & 1 & 1 & - & - & - & - & - & - & 02 \\
\hline Cys (C) & - & - & - & - & 1 & - & - & - & 1 & - & - & - & - & 02 \\
\hline Met (M) & - & - & - & - & 1 & - & 2 & - & - & 1 & - & 1 & 1 & 06 \\
\hline Asp (D) & - & - & 1 & - & - & - & - & 1 & - & 1 & 3 & - & 1 & 07 \\
\hline Asn $(\mathrm{N})$ & - & - & - & - & - & 2 & 1 & - & 1 & 2 & 2 & 5 & 5 & 18 \\
\hline Glu (E) & 1 & 1 & - & - & 1 & - & - & - & - & 1 & - & - & - & 04 \\
\hline Gln (Q) & - & - & - & 1 & - & - & - & 1 & - & 1 & - & 3 & 3 & 09 \\
\hline Phe (F) & - & 2 & 1 & 1 & 2 & 1 & 1 & - & 1 & 1 & - & 1 & 2 & 13 \\
\hline $\operatorname{Tyr}(\mathrm{Y})$ & - & 2 & 1 & 1 & - & - & - & - & - & - & 1 & 1 & 1 & 07 \\
\hline Try (W) & - & - & - & - & - & 1 & - & 1 & - & - & 1 & - & - & 03 \\
\hline Lys (K) & 1 & - & - & 1 & - & 2 & 1 & - & 2 & 1 & - & 1 & 1 & 10 \\
\hline $\operatorname{Arg}(\mathrm{R})$ & - & 1 & 1 & 1 & 1 & - & 1 & 1 & 1 & - & 1 & - & 1 & 09 \\
\hline His $(\mathrm{H})$ & - & - & 1 & - & - & - & - & 1 & 1 & - & 1 & 1 & 1 & 06 \\
\hline Pro (P) & - & - & 1 & - & - & 1 & 1 & 1 & 2 & - & - & - & 一 & 06 \\
\hline Total & 08 & 07 & 08 & 10 & 09 & 10 & 14 & 13 & 16 & 16 & 16 & 20 & 24 & 171 \\
\hline Peak number & 02 & 18 & 19 & 27 & 30 & 31 & 52 & 54 & 67 & 70 & 73 & 90 & 98 & - \\
\hline
\end{tabular}

A: N2T1; B: N2T2; C: N2T3; D: N2T4; E: N2T5; F: N2T6; G: N2T7;

H: N2T8; I: N2T9; J: N2T10; K: N2T11; L: N2T12 and M: N2T13 Peptides.

TABLE 3: Comparison of N-terminal sequences of Nivulian-II with other known cysteine proteases.

\begin{tabular}{lcccccccccccccccc}
\hline Source & Enzyme & \multicolumn{1}{c}{} & \multicolumn{1}{c}{ Sequence* $^{*}$} & \multicolumn{1}{c}{ Identities } & Positives \\
\hline Euphorbia nivulia & Nivulian-II & D & F & P & P & N & T & C & C & C & I & C & C & - & - \\
Opisthorchis viverrini & Cathepsin F & M & R & P & F & V & C & C & V & L & V & T & T & $2 / 12(16.66)$ & $3 / 12(25.00)$ \\
Streptococcus pyogenenes & IdeS & K & S & C & D & K & T & H & T & C & P & P & C & $3 / 12(25.00)$ & $3 / 12(25.00)$ \\
Zingiber officinale & GP-I & D & V & L & P & D & S & I & D & W & R & E & K & $2 / 12(16.66)$ & $3 / 12(25.00)$ \\
Zingiber officinale & GP-II & D & D & L & P & D & S & I & D & W & R & E & N & $2 / 12(16.66)$ & $3 / 12(25.00)$ \\
Pineapple stem & Bromelain & - & A & V & P & Q & S & I & D & W & R & D & Y & $1 / 12(08.33)$ & $2 / 12(16.66)$ \\
Rat liver & Cathepsin J & D & T & P & A & N & E & T & Y & P & D & L & L & $3 / 12(25.00)$ & $3 / 12(25.00)$ \\
\hline
\end{tabular}

${ }^{*}$ Shared amino acids as bold.

ubiquitin I, cytochrome $\mathrm{C}$, and myoglobin) were used as standards for mass calibration.

2.4. Peptide Analysis. For peptide mass fingerprinting, the targeted protein band (spot) was manually excised from the gel and was processed for MS and MS/MS analysis as described previously [9]. In brief, gel pieces were washed twice with $50 \%(\mathrm{v} / \mathrm{v})$ acetonitrile in $50 \mathrm{mM}$ ammonium bicarbonate, shrunk by dehydration in acetonitrile and dried in vacuum centrifuge. Disulfide bonds were reduced by incubation with $10 \mathrm{mM}$ dithiothreitol (DTT) in $50 \mathrm{mM}$ ammonium bicarbonate for $45 \mathrm{~min}$ at $56^{\circ} \mathrm{C}$. Alkylation was performed by replacing the DTT solution with $55 \mathrm{mM}$ iodoacetamide in $50 \mathrm{mM}$ ammonium bicarbonate. After 30 min incubation at $25^{\circ} \mathrm{C}$ in the dark, the gel pieces were washed with $50 \%(\mathrm{v} / \mathrm{v})$ acetonitrile in $50 \mathrm{mM}$ ammonium bicarbonate, shrunk by dehydration in acetonitrile, and dried in vacuum centrifuge. The dried gel pieces were incubated with sequencing-grade modified trypsin at $37^{\circ} \mathrm{C}$ overnight. To extract the tryptic digested peptides, $0.1 \%$ trifluoroacetic acid in acetonitrile was added, the samples were sonicated for $5 \mathrm{~min}$ and the separated supernatant was dried under vacuum. Then, the samples (peptides) were desalted using a Ziptip C 18 (Millipore, USA) according to the manufacturer's protocol. MALDI-MS measurements were performed using MALDI TOF/MS in reflectron mode using $\alpha$-cyano4-hydroxycinnamic acid as a matrix. All mass spectra were 
TABLE 4: Comparison of N-terminal sequence of Nivulian-II with other matched fragments of known cysteine proteases.

\begin{tabular}{llllllllllllllll}
\hline Source & Type & & & \multicolumn{1}{c}{ Sequence $^{*}$} & \multicolumn{1}{c}{} & \multicolumn{1}{c}{ Identities } & Positives \\
\hline Euphorbia nivulia & Cysteine & D & F & P & P & N & T & C & C & C & I & C & C & - & - \\
Naegleria gruberi & Cysteine & D & F & P & P & N & E & T & S & L & G & F & S & $5 / 12(41.66 \%)$ & $6 / 12(50.00 \%)$ \\
Polysphondylium pallidum & Cysteine & V & I & E & P & N & T & S & C & I & I & I & P & $5 / 12(41.66 \%)$ & $5 / 12(41.66 \%)$ \\
Ricinus communis & Cysteine & C & P & D & G & N & T & C & C & C & I & Y & E & $6 / 12(50.00 \%)$ & $6 / 12(50.00 \%)$ \\
Hevea brasiliensis & Cysteine & C & P & E & S & N & T & C & C & C & I & F & E & $6 / 12(50.00 \%)$ & $6 / 12(50.00 \%)$ \\
Saccoglossus kowalevskii & BP-10 & G & P & A & P & N & S & C & C & I & I & A & M & $5 / 12(41.66 \%)$ & $7 / 12(58.33 \%)$ \\
Mycoplasma hominis & MAP & V & G & F & P & N & T & C & C & I & S & V & N & $5 / 12(41.66 \%)$ & $5 / 12(41.66 \%)$ \\
\hline
\end{tabular}

${ }^{*}$ Shared amino acids as bold .

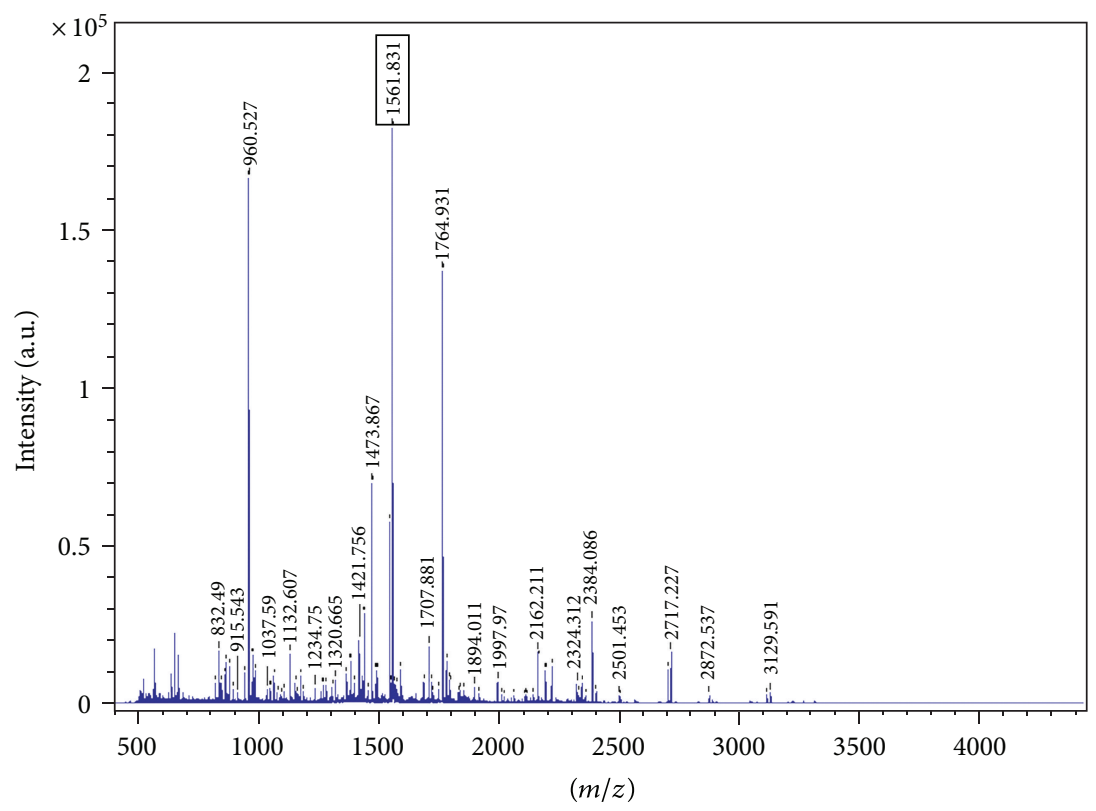

FIGURE 2: MALDI-TOF mass spectrum of trypsin-digested peptide map of Nivulian-II.

internally calibrated with trypsin autolysis peaks. Peptide mass fingerprinting (PMF) was carried out using MASCOT Matrix Sciences (London, UK) program for protein identification (http://www.matrixscience.com/). MALDI-TOF/TOF fragment ion analysis (see Figure S1 in supplementary Material available online at http://dx.doi.org/10.1155/2013/569527) of selected individual parent peptide (Figure S2) was carried out in the LIFT mode of the instrument. Then, in order to further confirm the identification, all MS/MS data from LIFT TOF/TOF spectra were combined with the corresponding MS peptide mass fingerprinting data for database searching.

The spectra were analyzed with flex-Analysis software (Version 3.2, Bruker-Daltonics, Germany) and searched against two taxonomies: (i) other green plants and (ii) species information unavailable in the NCBI (NCBInr) and MSDB database using MASCOT software (Version 2.2). The PMF search parameters were: $100 \mathrm{ppm}$ tolerance as the maximum mass error, $\mathrm{MH}^{+}$monoisotopic mass values, allowance of oxidation (M) modifications, allowed for 1 missed cleavage, and fixed modification of cysteine by carboxymethyl, that is, Carbamidomethylation (C) [10].

2.5. N-Terminal Amino Acid Sequence Analysis. The purified protease enzyme was adsorbed onto a PVDF membrane and washed several times with deionised water. The N-terminal sequence was determined by Pehr Edman's automated degradation method using a Procise protein sequencing system (Applied Biosystem) composed of four integrated modules. This system sequentially cleaves N-terminal amino acids from protein and analyzes the resulting phenylthiohydantoin (PTH) amino acid residues. Protein homology searches were performed using the BLAST [11], indicating the specific residues which are identical "identities" as well as those which are nonidentical, but nevertheless have positive alignment scores "Positives".

\section{Results and Discussion}

Euphorbia nivulia Buch.-Ham. belongs to the Euphorbiaceae family, whose members are characterized by secretory tissues (laticifers) which frequently include proteolytic and milk clotting enzymes. The young stem latex of E. nivulia possesses proteolytic and milk clotting enzyme in more quantity as compared with other investigated laticiferous plants of Northern region of Maharashtra, India [5]. E. nivulia latex contains thermostable glycosylated cysteine protease having 6.6 and $45^{\circ} \mathrm{C}$ are, respectively, optimum $\mathrm{pH}$ and 


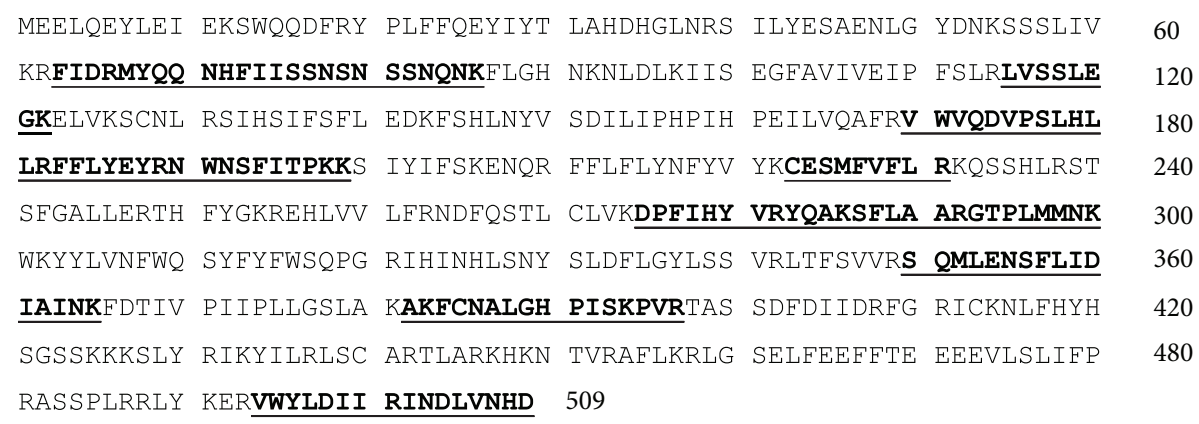

(a)

MAQKILEHLE RNLPTPKEKS AELRLATSWK KSLSSNNNNS LANGPDSLRK PDQADKTNSA QATEDRGNLL FKFAPREVTV QADSAAKDNT SASDMKAVPN AASSEFPSFQ KKPPTHSSGN KPVLSSITVG KPDQRWALSS DKTTSGFTFP VSATSGVNSE PPTPTIMPST SATVPSPPKD ASSIPSYSFG SKKSDPALVF SFPSTSNASI PDNASSDLKF KFGSEKTTRL SFSSIGKDAI CY 242
60

120

180

240

300

360

420

80

60

120

180

240

(b)

Figure 3: (a) Peptides of Nivulian-II matched with Maturase K (Q52ZV1_9MAGN) of Banksia quercifolia. (b) Peptides of Nivulian-II matched with unknown protein (gi|118485477) of Populus trichocarpa.

temperature, molecular weight is about $43.42 \mathrm{kDa}$ (SDSPAGE), cysteine hydrochloride activator, and inhibitor is mercuric chloride [5]. According to protease nomenclature, this protein is designated as Nivulian-II due to previously Nivulian-I (31486.985 Da) was already characterized from $E$. nivulia latex [8].

Mass spectroscopy (Figure 1) revealed that Nivulian-II had a molecular mass of 43670.846 Dalton $(43.67 \mathrm{kDa})$, which is relatively matched with molecular mass determined by SDS-PAGE, that is, $43.42 \mathrm{kDa}[5,12]$. Similar molecular pattern was also recorded in the molecular mass measurement of Funastrain CII [13]. The resulted molecular mass, that is, $43.67 \mathrm{kDa}$ is very close to those of other peptidase belonging to cysteine protease family for example cysteine proteases of Vigna mungo, 'Curcuma longa, Taenia crassiceps, Allomyces aebuscula, Triticum arstivum, Haemonchus contortus, and Gymnophalloides seoi [12].

Out of total trypsin-digested peptide fragments (Figure 2) of Nivulian II, only thirteen peptides that is, $28.50 \%$ sequence was hit in MSDB (mass spectrometry protein sequencing database) by Mascot peptide fingerprint search engine with Maturase K (Q52ZV1_9MAGN) of Banksia quercifolia (Family: Proteaceae) with 67.1 score and $P<0.05$ (Figure 3(a)). An additional match of the mascot peptide mass fingerprint of Nivulian-II with other existing protein sequence from NCBI (National Center for Biotechnology Information) database was also performed. One of the unknown protein (gi|118485477) of Populus trichocarpa (Family: Salicaceae), matches 7 peptides (i.e., $25.2 \%$ sequence) of Nivulian-II as shown in Figure 3(b) (http://www.matrixscience.com/).

The mass spectrum showed several protonated ions $[\mathrm{M}+\mathrm{H}]^{+}$of the peptide fragments. As listed in Table 1, the ions at $832.490,1037.590,1046.635,1154.597,1188.631$, $1234.750,1552.775,1561.831,1794.938,1852.035,1997.970$,
2357.131, and 2872.537 were the thirteen trypsin digested peptides corresponding to residues $115-122$, 183-189, 275282, 283-292, 223-231, 190-199, 287-300, 170-182, 382-397, 350-365, 494-509, 67-86 and 63-86. These were designated as N2T1, N2T2, N2T3, N2T4, N2T5, N2T6, N2T7, N2T8, N2T9, N2T10, N2T11, N2T12, and N2T13, respectively. As depicted in Table 1, peptide mass profiles were obtained from the database search engine and amino acid sequence of individual peptides were identified from known sequence of Maturase K of Banksia quercifolia from desired spot of NivulianII protein of SDS-PAGE. Table 2 summarizes the amino acid composition of obtained peptide fragments (N2T1 to N2T13) of Nivulian-II by trypsin digestion. Only two residues of $\mathrm{OH}$ group and S-containing amino acid, that is, threonine $(\mathrm{T})$ and cysteine (C), were recorded in sequenced peptides. A total of 171 amino acids were sequenced from Nivulian-II protein. The content of serine (11.65\%) and asparagine (10.52\%) was abundant in sequenced peptides of Nivulian-II.

The N-terminal amino acid sequence of cysteine protease named as Nivulian-II was deposited in the universal protein resource database, "Uniprot" under the accession number P86837. A comparative study of homology of N-terminal sequences of various cysteine proteases with P86837 using BLAST algorithm network services (http://blast.ncbi.nlm.nih.gov/Blast.cgi) was conducted. The $\mathrm{N}$-terminal sequence of Nivulian-II was aligned with those of other plant cysteine proteases and showed 25-50\% identity with other cysteine peptidases (Tables 3 and 4). The isoleucine (I) is present on the 10th position from N-terminal side of Nivulian-II, which is fully homologous with isoleucine of Maturase $\mathrm{K}$, as it is present on the 10th position from amino terminal side (Figure 3(a)).

N-terminal sequence of Nivulian-II shows only $25 \%$ homology sequence with plant origin cysteine proteases, that is, GP-I and GP-II of Zingiber officinale rhizome [14]. It 
shows $16.66 \%$ similarity with bromelain of pineapple stem protease [15]. It is also homologous with some animal origin cysteine protease, that is, cathepsin F [16] and cathepsin J [17] and bacterial cysteine protease, that is, IdeS of Streptococcus pyogenes [18]. This sequence showed higher identity (50\%) with other cysteine endopeptidase isolated from the latex of rubber tree, Hevea brasiliensis Muell, Arg [19], and a member of the Euphorbiaceae family, that is, Ricinus communis. It is also homologous (41.66\%) with some microbial origin cysteine proteases of Naegleria gruberi [20] and Polysphondylium pallidum, sulphur-containing protease, that is, Methionine protease (MAP) of Mycoplasma hominis and blastula-like protease (BP-10) of Saccoglossus kowalevskii. Nivulian-II shared the motifs surrounding the catalytic cysteine (NT and $\mathrm{CCI}$ ) that also occurred in most of the sequences compared (Table 4). The asparagine $(\mathrm{N})$ is notably conserved and it is present in all the cases as well as the cysteine residue located in position 8 .

In the light of all these experimental observations it is envisaged that the present cysteine protease, Nivulian-II, is characterized for the first time. N-terminal amino acid sequence and tryptic digestion profile of nivulian infer the exclusive nature of enzyme and it may be a novel protease of the cysteine family.

\section{Conflict of Interests}

None of the authors declare any competing financial interests.

\section{Authors' Contribution}

Both authors contributed equally in the design and performance of research, in the analysis of data, and writing in the paper.

\section{Acknowledgments}

The authors are thankful to Dr. Surekha Zingde, Director, Advanced Centre for Treatment, Research and Education in Cancer (ACTREC), Mumbai, India, for generously allowing the use of MALDI-TOF/MS facility. They are extremely grateful to professor Sathees Raghavan, Department of Biochemistry, Indian Institute of Science (IISc), Bangalore, India, for helping in determination of $\mathrm{N}$-terminal amino acid sequence.

\section{References}

[1] R. T. Mahajan and S. B. Badgujar, "Biological aspects of proteolytic enzymes: a review," Journal of Pharmacy Research, vol. 3, no. 9, pp. 2048-2068, 2010.

[2] N. M. Rawlings and A. J. Barrett, Handbook of Proteolytic Enzymes, vol. 2, Academic Press, London, UK, 2nd ed edition, 2004.

[3] C. Sequeiros, M. J. Torres, S. A. Trejo, J. L. Esteves, C. L. Natalucci, and L. M. I. López, "Philibertain g I, the most basic cysteine endopeptidase purified from the latex of Philibertia gilliesii hook. et Arn. (Apocynaceae)," The Protein Journal, vol. 24, no. 7-8, pp. 445-453, 2005.
[4] V. Kumar Dubey and M. V. Jagannadham, "Procerain, a stable cysteine protease from the latex of Calotropis procera," Phytochemistry, vol. 62, no. 7, pp. 1057-1071, 2003.

[5] S. B. Badgujar and R. T. Mahajan, "Comparison of cysteine proteases of four laticiferous plants and characterization of Euphorbia nivulia Buch.-Ham. latex glycosylated cysteine peptidase," Indian Journal of Natural Products and Resources, vol. 3, no. 2, pp. 152-160, 2012.

[6] R. T. Mahajan and S. B. Badgujar, "Bioprospecting of Euphorbia nivulia Buch.-Ham.," International Journal of Phytopharmacology, vol. 2, no. 2, pp. 37-42, 2011.

[7] S. B. Badgujar and R. T. Mahajan, "Characterization of milk clotting cysteine protease of Euphorbia nivulia Buch.-Ham. latex," Green Farming, vol. 1, no. 6, pp. 645-648, 2010.

[8] S. B. Badgujar and R. T. Mahajan, "Characterization of 31-kDa, Tubulin alpha-1 chain like protein of Euphorbia nivulia Buch.Ham. latex," Biochemistry: An Indian Journal, vol. 5, no. 4, pp. 258-262, 2011.

[9] S. L. Cohen and B. T. Chait, "Mass spectrometry of whole proteins eluted from sodium dodecyl sulfate- polyacrylamide gel electrophoresis gels," Analytical Biochemistry, vol. 247, no. 2, pp. 257-267, 1997.

[10] X. Wang, M. Shi, X. Lu et al., "A method for protein extraction from different subcellular fractions of laticifer latex in Hevea brasiliensis compatible with 2-DE and MS," Proteome Science, vol. 8, article 35, 2010.

[11] S. F. Altschul, T. L. Madden, A. A. Schäffer et al., "Gapped BLAST and PSI-BLAST: a new generation of protein database search programs," Nucleic Acids Research, vol. 25, no. 17, pp. 3389-3402, 1997.

[12] S. B. Badgujar, Proteolytic enzymes of some latex bearing plants belonging to Khandesh region of Maharashtra [Ph.D. thesis], North Maharashtra University, Jalgaon (Maharashtra State), India, 2011.

[13] S. R. Morcelle, S. A. Trejo, F. Canals, F. X. Aviles, and N. S. Priolo, "Funastrain c II: a cysteine endopeptidase purified from the latex of Funastrum clausum," Protein Journal, vol. 23, no. 3, pp. 205-215, 2004.

[14] K. H. Choi and R. A. Laursen, "Amino-acid sequence and glycan structures of cysteine proteases with proline specificity from ginger rhizome Zingiber officinale," European Journal of Biochemistry, vol. 267, no. 5, pp. 1516-1526, 2000.

[15] J. B. Bouwstra, E. C. Spoelstra, P. De Waard, B. R. leeflang, J. P. Kamerling, and J. F. G. Vliegenthart, "Conformational studies on the N-linked carbohydrate chain of bromelain," European Journal of Biochemistry, vol. 190, no. 1, pp. 113-122, 1990.

[16] P. Pinlaor, N. Kaewpitoon, T. Laha et al., "Cathepsin F cysteine protease of the human liver fluke, Opisthorchis viverrini," PLoS Neglected Tropical Diseases, vol. 3, no. 3, article no. e398, 2009.

[17] T. Nikawa, T. Towatari, and N. Katunuma, "Purification and characterization of cathepsin J from rat liver," European Journal of Biochemistry, vol. 204, no. 1, pp. 381-393, 1992.

[18] U. Von Pawel-Rammingen, B. P. Johansson, and L. Björck, "IdeS, a novel streptococcal cysteine proteinase with unique specificity for immunoglobulin G," The EMBO Journal, vol. 21, no. 7, pp. 1607-1615, 2002.

[19] S. Q. Peng, J. H. Zhu, H. L. Li, and W. M. Tian, "Cloning and characterization of a novel cysteine protease gene $(\mathrm{HbCP})$ from Hevea brasiliensis," Journal of Biosciences, vol. 33, no. 5, pp. 681690, 2008.

[20] L. K. Fritz-Laylin, S. E. Prochnik, M. L. Ginger et al., "The genome of Naegleria gruberi illuminates early eukaryotic versatility," Cell, vol. 140, no. 5, pp. 631-642, 2010. 

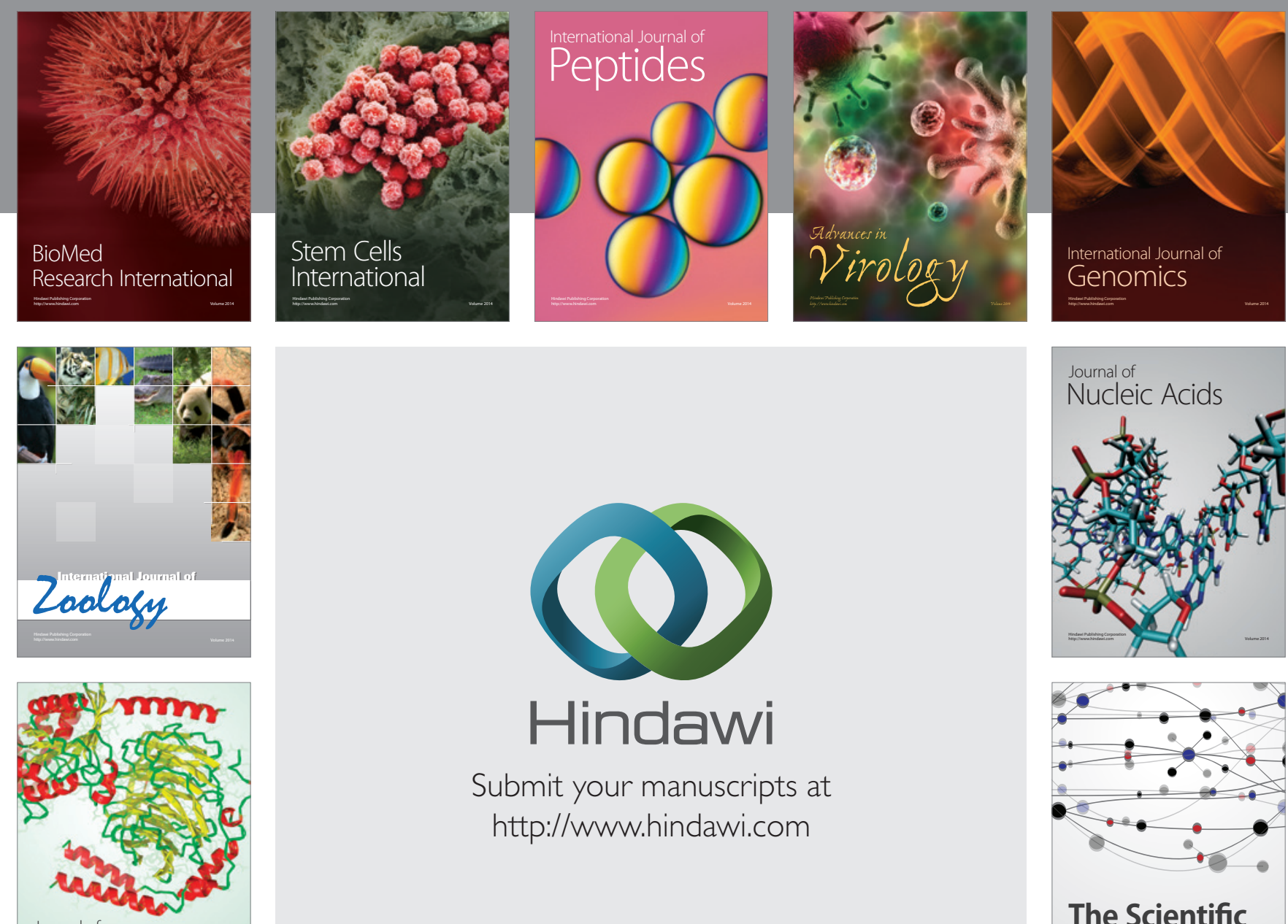

Submit your manuscripts at

http://www.hindawi.com

Journal of
Signal Transduction
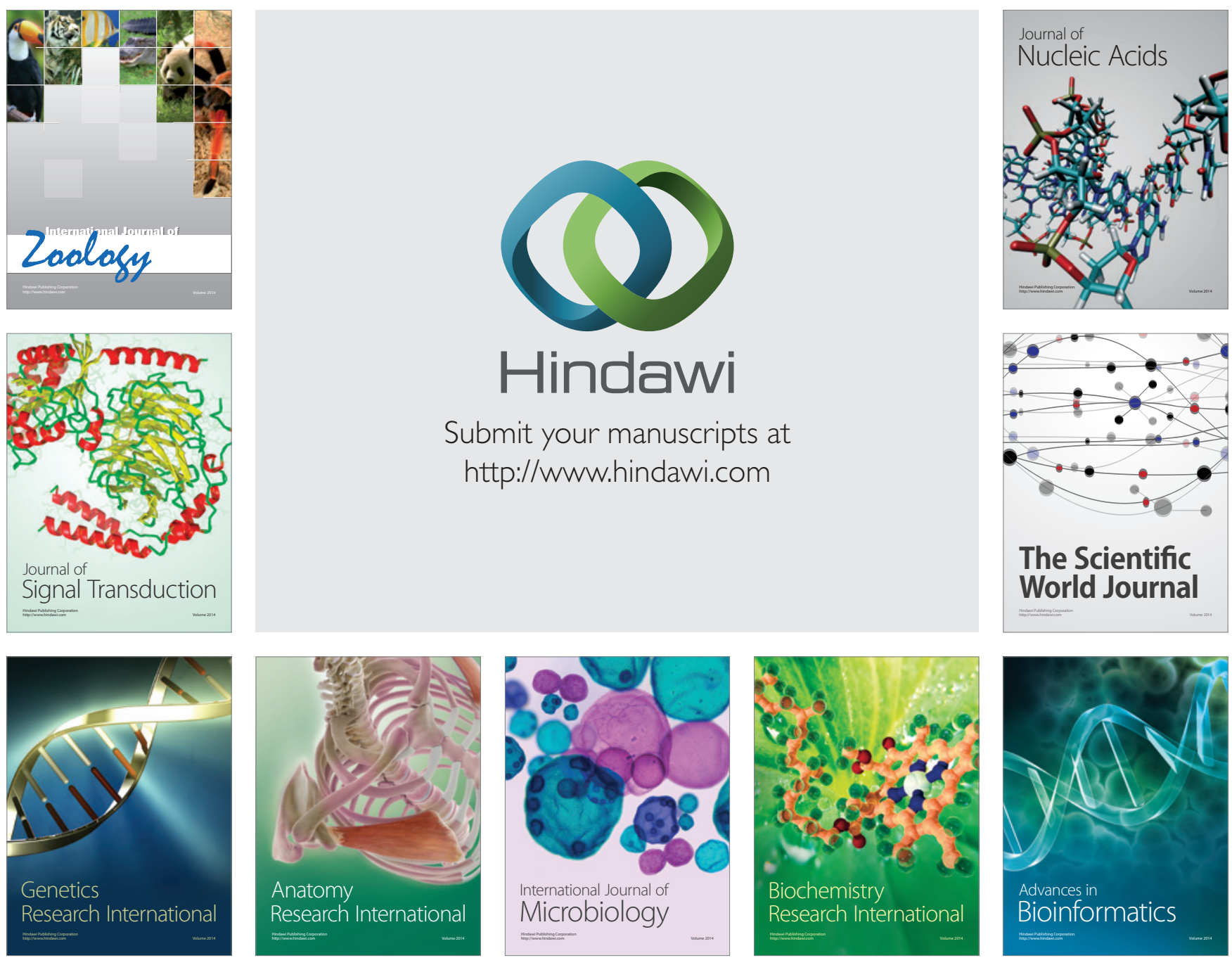

The Scientific World Journal
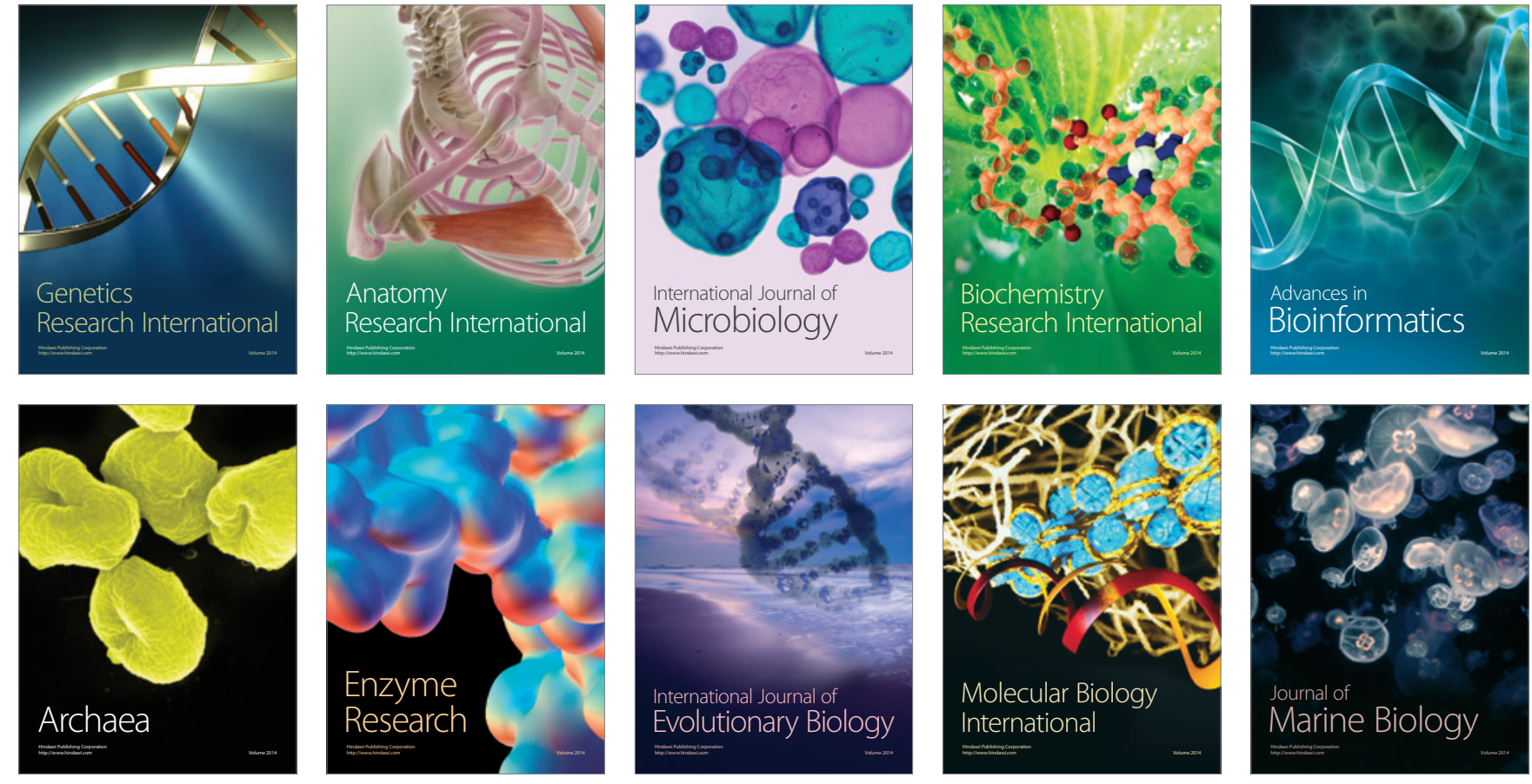